\title{
APONTAMENTOS SOBRE A CONSTITUIÇÃO DO ESTADO EM J. J. ROUSSEAU
}

\author{
Mateus Mioto dos Santos ${ }^{1}$ \\ miotto mateus@hotmail.com \\ Universidade Estadual do Oeste do Paraná - UNIOESTE
}

\begin{abstract}
RESUMO
É considerável compreender as partes constituintes do Estado para Rousseau em nossos dias, de modo que as sociedades modernas enfrentam crises democráticas nas quais, a falência da representatividade se confunde com a insuficiência dos argumentos do autor. Com o presente artigo, intentamos ainda propor uma alternativa de interpretação ao problema fundamental do pensamento de Rousseau, que consiste na constituição de um novo cidadão, produto de um contrato social que precipuamente o tornaria mais humano por meio de uma desnaturação. Nesse sentido, relevamos a questão do direito à igualdade, que passa por alterações na medida em que a liberdade natural é substituída pela liberdade convencional. Em consequência, analisamos o processo de composição da moral do homem, que de forma abrangente considera os elementos levantados anteriormente.

Palavras-chave: Filosofia Política; Contrato Social; Estado. Moral.
\end{abstract}

\section{NOTES ON THE STATE CONSTITUTION IN ROUSSEAU}

\begin{abstract}
It is important to understand the constituent parts of the state to Rousseau in our day, so that modern societies face democratic crises in which the failure of representation is intertwined with the failure of the author's arguments. With this article, still intend to propose an alternative interpretation of the fundamental problem of Rousseau's thought, which is the formation of a new citizen, the product of a social contract that would make him more human precipuamente through a denaturing. Accordingly, I will address the question of the right to equality, which undergoes changes in that natural liberty is replaced by conventional freedom. Accordingly, we analyze the composition process of man's moral, which comprehensively considers the elements raised previously.
\end{abstract}

Keywords: Political Philosophy; Social Contract; State; Moral.

\section{Proêmio}

Consideramos que Jean Jacques Rousseau (1712-1778) foi um dos pensadores se não mais radical, ao menos o mais peculiar do século XVIII. Sua filosofia, embora contratualista $^{2}$ era incongruente em determinados pontos à de Locke (1632-1704), teórico considerado por inúmeros estudiosos o pai do liberalismo político - devido sua influência no processo que será lembrado historicamente como Iluminismo. Por esse motivo, torna-se difícil encaixar a peça de Rousseau no quebra cabeças da filosofia iluminista. Ao contrário de Locke que atendia as expectativas da burguesia ascendente à época, Rousseau era associado mais correntemente à pequena burguesia, composta essencialmente por artesãos. A adstringência de Rousseau a parcela menos favorecida da burguesia, é decorrente de sua defesa à democracia participativa e a ideia de que o homem é bom por natureza e somente 
a sociedade o corrompe. Em suas obras Rousseau é perseverante ao demonstrar a importância substancial do povo nas decisões políticas. Ao passo que o soberano adquire consistência no Contrato Social (1999), suas características são igualmente evidenciadas:

Afirmo, pois, que a soberania, não sendo senão o exercício da vontade geral, jamais pode alienar-se, e que o soberano, que nada é senão um ser coletivo, só pode ser representado por si mesmo. O poder pode transmitir-se; não, porém, a vontade. (ROUSSEAU, 1999, p.86)

Indivisível e inalienável, eis as características essenciais do soberano. Inalienável, pois, tendo a coletividade como atributo incondicional para existir não há como alienar parte de si (apenas um sujeito) sem comprometer os outros "contratantes" e da mesma forma o soberano não pode ser representado por terceiros, mas sim única e exclusivamente por si só. A esse respeito Rousseau escreve:

Mas o corpo político ou soberano, não existindo senão pela integridade do contrato, não pode obrigar-se, mesmo com outrem, a nada que derrogue esse ato primitivo, como alienar uma parte de si mesmo ou submeter-se a um outro soberano. Violar o ato pelo qual existe seria destruir-se, e o que nada é nada produz. ( ROUSSEAU, 1999, p.74)

Acerca da sua indivisibilidade devemos ressaltar a questão "judicial". Rousseau declara que para a vontade geral ser convertida em lei é preciso que a mesma seja externalizada pelo soberano, para tanto é necessário que haja votações e assembleias nas quais ainda que não se obtenha a unanimidade, sejam ouvidos todos os membros do soberano. Ademais, o autor adverte sobre o desacerto que é a divisão do soberano:

Esse erro provém de não disporem de noções exatas sobre a autoridade soberana e de terem tomado por partes dessa autoridade o que não passa de emanações suas. Assim, por exemplo, tiveram-se por atos de soberania o ato de declarar guerra e o de fazer a paz, que não o são, pois cada um desses atos não é uma lei, mas unicamente uma aplicação da lei, um ato particular que determina o caso da lei, como claramente se verá quando for definida a idéia que se prede à palavra lei. ( ROUSSEAU, 1999, p.88)

Nesses enunciados de Rousseau, pautavam-se as críticas direcionadas a sociedade norteada pelos princípios da alta burguesia, perniciosa ao resto da população.

O objetivo deste trabalho, não é trazer à tona convergências e inconvergências da filosofia de Rousseau e de Locke. Haja vista que ambos conferiam ao estado natural do homem a paz reinante, salvo algumas diferenças de tratamento. Para Locke, no estado de natureza, os homens seriam impelidos sem haver alguma autoridade instituída a estabelecer relações pautadas no pensamento racional. Aufere-se desse fato, que segundo o autor d' $O$ Tratado sobre o governo, a atividade conjunta dos homens no chamado estado natural não tem limites, ao contrário das conclusões de Rousseau.

Se o filósofo inglês se aproxima de Rousseau ao julgar o estado de natureza como um mundo onde vigora a paz, dele Locke se distancia quando considera que os homens são conduzidos ali por uma lei natural que equivale à própria razão. Isso significa que o homem não seria, aos seus olhos, nada limitado. (ESPÍNDOLA, 2008. p. 75)

O autor do Contrato Social (1987) nos diz que, no estado natural os homens gozam de plena independência e liberdade. Suas relações com outros homens são norteadas pelo 
instinto de conservação e por sua piedade para com seus semelhantes, e, portanto seriam limitadas, posto que a relação contém objetivos um tanto quanto "tacanhos".

Em uma palavra, tal como deve ter saído das mãos da natureza, vejo um animal menos forte que uns, menos ágil que outros, mas, de maneira geral, o melhor organizado de todos. Vejo-o fartando-se sob um carvalho, saciando-se no primeiro riacho, encontrando seu leito ao pé da mesma árvore que lhe forneceu o repasto, e eis satisfeitas as suas necessidades. (ROUSSEAU, 1985. p. 53)

Contudo, ambos os pensadores sustentam a teoria de que a sociedade civil e política são constituídas por meio de um pacto, um contrato.

Pretendemos após uma breve introdução ao pensamento de Rousseau e adotando como referências básicas as obras seguintes do autor: Contrato Social; Discurso Sobre a Origem e os Fundamentos da Desigualdade Entre os Homens; esclarecer como Rousseau prevê, no momento em que uma determinada associação é estabelecida entre os homens, a troca da liberdade natural pela civil. Dessa forma, intentamos compreender de que modo a instituição da igualdade civil entre os homens corrompe as duas primeiras.

A passagem do estado de natureza para o estado civil determina no homem uma mudança muito notável, substituindo na sua conduta o instinto pela justiça e da as suas ações a moralidade que antes lhe faltava. (ROUSSEAU, 1987. p.31)

Do excerto acima podemos auferir que antes de constituir qualquer tipo de sociedade, de associação, os homens viviam em seu estado natural. Nesse estado, vivendo praticamente de maneira estática e regular, suas necessidades eram naturalmente satisfeitas devido ao caráter singelo de seu modo de vida livre e independente. Apenas bastava-lhe alimento, uma fêmea, e uma sombra na qual pudesse recostar-se.

Em um esforço de tentar determinar os direitos naturais e invioláveis dos homens que persistiriam após a instituição da sociedade civil, Rousseau afirma em seu Discurso Sobre a Origem e os Fundamentos da Desigualdade Entre os Homens (1985) que a tarefa de esclarecer "o que há de originário e de artificial na atual natureza do homem" é no mínimo onerosa, porém indispensável para a compreensão do estado em que os homens e seus direitos positivos encontram-se. E acrescenta: "Porém, enquanto não conhecermos o homem natural, em vão desejaremos determinar a lei que recebeu ou aquela que melhor convém à sua constituição". (ROUSSEAU, 1985. p.44) Portanto:

Analisar o homem em seu estado de natureza implica uma distinção entre o homem já sociabilizado e o homem anterior a qualquer tipo de sociedade, ou seja, implica questionar o homem em sua origem. Tal questionamento aponta para outra distinção ainda mais profunda, qual seja, a distinção entre aquilo que é essencial e o que é acidental no homem. (JORGE, 2011. p.95)

Vivendo apenas dos subsídios provenientes da natureza e se adaptando a ela, os progressos do homem natural não seriam equivalentes a sua imensa paz de espírito vivendo de tal forma. Entrementes, a mesma natureza que fornece as condições para viver tranquilamente, em determinado momento lhe fornece também obstáculos a sua sobrevivência e conservação. Logo, os homens não são mais capazes e fortes o suficiente para se manterem no estado natural e unem-se com um único objetivo, a sua conservação. 
Nesse momento, o estado natural deixa de existir, a livre vontade dos homens cingida pelo seu instinto e necessidade à conservação leva-os a estabelecerem uma associação formal cujo objetivo primariamente é unir suas forças e manter a segurança do grupo. Entretanto, as novas relações estabelecidas entre os homens agora "associados", imputam ao sócios um novo problema:

Encontrar uma forma de associação que defenda e proteja a pessoa e os bens de cada associado com toda a força comum, e pela qual cada um, unindo-se a todos, só obedece contudo a si mesmo, permanecendo assim tão livre quanto antes. Esse o problema fundamental cuja solução o contrato social oferece. (ROUSSEAU. 1999. p.69-70)

De qualquer forma, o que ocorre é a alienação ${ }^{3}$ integral dos homens e seus bens em benefício próprio e comum de todos os outros, ou seja, em prol de sua conservação. Bem como a suplantação dos interesses particulares pela vontade geral. Para que o dito se efetive e o Estado manifeste realmente os interesses comuns à sociedade, é imperativo que os homens organizem e tão logo o contrato seja firmado, um corpo coletivo, moral e político, representativo desses mesmos interesses, o qual ainda mantenha inalteráveis as cláusulas fundamentais do contrato social.

Nesse sentido, o autor indica que:

A primeira e a mais importante conseqüência decorrente dos princípios até aqui estabelecidos é que só a vontade geral pode dirigir as forças do Estado de acordo com a finalidade de sua instituição, que é o bem comum, porque, se a oposição dos interesses particulares tornou necessário o estabelecimento das sociedades, foi o acordo desses mesmos interesses que o possibilitou. $\mathrm{O}$ que existe de comum nesses vários interesses forma o liame social e, se não houvesse um ponto em que todos os interesses concordassem, nenhuma sociedade poderia existir. Ora, somente com base nesse interesse comum é que a sociedade deve ser governada. (ROUSSEAU, 1999. p.85)

Não obstante, a vontade geral é assinalada como escopo do Estado instituído e componente substancial onde repousa a coesão social. A vontade geral não pode ser reduzida ao conceito de "soma das vontades individuais", pois não vai ao encontro dessas. No âmago da vontade geral, está resguardado o que existe corriqueiramente na consciência coletiva, e o exercício do poder estatal ao qual Rousseau denomina soberania, é a materialização dessa essência.

Acompanhando o raciocínio de Rousseau quanto à distinção entre vontade geral e vontade de todos, há um excerto no Capítulo III do Livro Segundo do Contrato Social (1999) que exprime o fundamento de tal cisma. "Há comumente muita diferença entre a vontade de todos e a vontade geral. Esta se prende somente ao interesse comum; a outra, ao interesse privado, e não passa de uma soma das vontades particulares." (1999, p.91)

Novamente no Capítulo III, Rousseau (1999) afirma "que a vontade geral é sempre certa e tende sempre à utilidade pública", mas acrescenta que para tanto, é preciso "que não haja no Estado sociedade parcial ${ }^{4}$ e que cada cidadão só opine de acordo consigo mesmo." Atribuindo essas qualidades à vontade geral, Rousseau nos faz auferir acertadamente que o poder de preceituar as leis em geral pertence ao povo e representa $o$ cerne mesmo do Estado. Conforme o autor, a assembleia ou o governo é o que opera e potencializa a força pública em prol da vontade geral. Reunido para deliberar acerca das decisões públicas o povo constitui a assembleia, órgão mediador da relação entre os 
contratantes - os quais Rousseau nesse momento denomina soberano - e o Estado. Resguardadas as distinções de governo que Rousseau enumera no Contrato Social (1999), a assembleia irá sempre se apresentar como efetivação da plena participação do povo "na execução das leis" e na "manutenção da liberdade". (1999, p.136)

Basicamente o pacto pode ser resumido nos seguintes termos:

Cada um de nós põe em comum sua pessoa e todo o seu poder sob a direção suprema da vontade geral, e recebemos, enquanto corpo, cada membro como parte indivisível do todo. (ROUSSEAU, 1999. p.71)

O cerne do pensamento de Rousseau pode ser considerado o momento em que o povo torna-se povo. $\mathrm{O}$ ato pelo qual o estado natural é suplantado pela instituição da sociedade civil. Ou seja, o contrato social. Entretanto, existem outros temas que permeiam e garantem a consistência de seu pensamento, como por exemplo, o conceito de igualdade.

Apesar de podermos situar conceitualmente o movimento iluminista durante o século XVIII, suas raízes remontam a expansão marítima e ao Renascimento Cultural, bem como pode ser associado à ascensão da burguesia nos séculos seguintes. A noção de igualdade, tese liberal com a qual trabalhamos atualmente, é herança desse movimento histórico. Embora a igualdade tenha consolidado-se como um individualismo ${ }^{5}$, ao longo da história existiu inúmeras acepções para esse termo. Rousseau ao lado de Hobbes e Locke é responsável pela legitimação do conceito de igualdade no campo político e jurídico.

As desigualdades sociais estariam arraigadas fundamentalmente na institucionalização da propriedade privada segundo Rousseau. Sendo esse fato irreversível, em sua ocorrência os homens deveriam formular maneiras de lidar com ela, sem excluir o problema radical. Dessa forma Rousseau prevê a igualdade de deveres e direitos para todos os cidadãos como resposta ao problema. Porém, como conciliar igualdade e liberdade? Quais são as decorrências de tais problemas?

\section{A troca da liberdade natural pela convencional e suas consequências no processo de constituição do direito à igualdade social}

Rousseau em sua obra mais conceituada o Contrato Social (1987), uniu justiça à utilidade e formulou o que seriam as bases legítimas sobre as quais deveríamos assentar nossos direitos e deveres, segundo a democracia representativa. Muito embora seu tratado idealizado, que se ocupa principalmente da construção do cidadão emergente de uma associação humana, nos apresenta clausulas passíveis de análise se supormos sua aplicação. Nesse trabalho, estipulado os seus limites, nos deteremos primeiramente em um: a troca da liberdade natural pela convencional (ou civil) e as consequências decorrentes de tal substituição, pois:

A ordem social, porém, é um direito sagrado que serve de base a todos os outros. Tal direito, no entanto, não se origina da natureza: funda-se, portanto em convenções. Trata-se, pois, de saber que convenções são essas. (ROUSSEAU, 1987. p. 22-23)

Para compreendermos o conceito de liberdade natural utilizado por Rousseau é mister delinearmos minimamente o estágio de desenvolvimento dos homens antes de realizarem o contrato social, ou seja, em seu estado natural.

A liberdade natural e a piedade como reguladoras da conservação da espécie humana em seu estado natural constituíram os pilares da ética do homem selvagem. Nas palavras do autor, "Ele tinha, unicamente no instinto, tudo de que precisava para viver em 
estado de natureza." (ROUSSEAU, 1981. p. 72) Em tal estado os homens viveriam em plena liberdade e independência primitivas, sem estabelecer qualquer forma de relacionamento. Nem mesmo a família ${ }^{6}$ se manteria unida, pois a lei primordial do homem natural consiste em zelar pela própria conservação,

Seus primeiros cuidados são aqueles que se deve a si mesmo, e assim que alcança a idade da razão, sendo o único juiz dos meios adequados para conservar-se, torna-se, por isso, senhor de si. (ROUSSEAU, 1987. p. 23)

Com esse discurso, Rousseau expressa que: todo homem pode considerar-se livre desde seu nascimento; não obstante, tão logo possa viver de maneira solitária e independente ele o fará; se uma porção de homens celebra um pacto é em benefício próprio, tendo como fim sua conservação; a partir do momento em que o pacto é estabelecido sua naturalidade é violada.

No momento em que as premissas da vida natural não são mais suficientes para garantir-lhes a própria existência, os homens renunciam a sua liberdade e independência primitivas alienando-as e celebrando um pacto social. Contudo, é em tal ato primevo que está contido o problema ao qual o contrato seria a solução. De acordo com Rousseau:

Encontrar uma forma de associação que defenda e proteja a pessoa e os bens de cada associado com toda a força comum, e pelo qual cada um, unindo-se a todos, só obedece, contudo a si mesmo, permanecendo assim tão livre quanto antes. (ROUSSEAU, 1987. p.32)

O contrato oriundo de uma necessidade já citada tem, portanto suas cláusulas uniformizadas. Rousseau as resume em apenas uma, "a alienação total de cada associado, com todos os seus direitos, à comunidade toda." (ROUSSEAU, 1987. p.32) E acrescenta que a mínima alteração da clausula una, expiraria a validade do contrato.

Os prolegômenos do Contrato Social (1987) devem ser compreendidos melhor, com a pressuposta leitura do mesmo. Esclareceremos adiante de forma sucinta as transfigurações ocasionadas pelo contrato na vida dos homens que o realizam, com o objetivo de tornar clara a explanação seguinte, a respeito da "troca de fundamento" na sociedade.

Nos dois capítulos que findam o Livro Primeiro do Contrato Social (1987), estão contidas as ideias que consequentemente geraram esse trabalho e que servem aqui de ferramenta para condensarmos o pensamento de Rousseau na busca da explanação prometida no parágrafo anterior e igualmente nos valerá como proêmio à ideia central desse artigo.

Primeiramente Rousseau declara:

A passagem do estado de natureza para o estado civil determina no homem uma mudança muito notável, substituindo na sua conduta o instinto pela justiça e dando às suas ações a moralidade que antes lhe faltava. (ROUSSEAU, 1987. p.36)

O excerto é fundamental, pois nele estão encerradas de forma velada ideias de suma importância. Como por exemplo, a de que o homem em seu estado natural não possuía verdadeiramente uma conduta moral, pois Rousseau defende a ideia de que o homem supera sua condição amoral por meio do estabelecimento do contrato, uma vez que o cisma entre sujeito e Estado é impraticável no pensamento de Rousseau. Se algum sujeito desejasse viver fora do Estado ele não desenvolveria plena vida moral por não participar da vida política de sua nação, enquanto que o Estado depende da moral integra e individual de 
cada cidadão. Portanto a atividade moral é recíproca, porém em níveis diferentes entre sujeito e Estado como nos mostra o texto de Maruyama:

$\mathrm{Na}$ Associação política - a forma mais acabada das associações civis enquanto produto de uma convenção -, a existência torna-se relativa, isto é, dependente do corpo social, e se faz, por definição, incompatível com as inclinações naturais, pois, em última instância, aquele que segue unicamente as inclinações naturais, ou seja, o homem natural, não tem nenhuma noção de dever ou obrigação. (2001. p.32)

A contraposição entre estado natural e estado civil acentua-se quando Rousseau esclarece verdadeiramente, o que o homem ganha e o que lhe é furtado por meio da instituição do contrato:

O que o homem perde pelo contrato social é a liberdade natural e um direito ilimitado a tudo quanto aventura e pode alcançar. O que com ele ganha é a liberdade civil e a propriedade de tudo quanto possui. (ROUSSEAU, 1987. p. 36)

Há, portanto uma transfiguração ou transvalorização do conceito de liberdade. Esse fato ocorre basicamente porque a liberdade natural é ameaçada pelos primeiros traços de civilização que o estado natural impinge aos homens, como por exemplo, a propriedade privada. Em decorrência disso a mesma transfiguração ocorre, pois, nos fundamentos morais e basilares da nova sociedade. De acordo com Rousseau, a troca da liberdade natural pela convencional é inevitável e necessária na manutenção da igualdade após o contrato. Pois, segundo ele ao efetuar-se a passagem, as diferenças naturais não são convertidas em desigualdades sociais.

Em seu estado natural o homem é livre e independente, o que ligeiramente leva-nos a concluir que seu único objetivo é conservar-se. Em outros termos, o objeto de suas ideias, de seus sentidos e de suas ações é ele mesmo e não há limites para isso. Quando o limite é impingido a ele, e este já não consegue manter-se vivo sozinho e realiza um pacto, estabelece-se então, a liberdade convencional. A liberdade não é mais causa, consequência de sua natureza e modo de vida, ela torna-se necessária não só para um sujeito, mas para um grupo de sujeitos. À liberdade instituída socialmente confere-se então a condição de atributo não só dos homens, mas igualmente do Estado, porque constitui premissa à igualdade de forma que todos têm o dever e o direito de participar livremente da vida política do Estado.

A troca da concepção de liberdade ocorre e por isso influência até certo ponto as relações sociais futuras. Muito embora trabalhemos com a ideia de que o elemento que verdadeiramente fundamentará a sociedade após o contrato é a igualdade, devemos admitir que se o mesmo não for corrompido e fundar-se na necessidade humana de conservação, a liberdade ainda que posta em segundo plano no estabelecimento do pacto não é corrompida. É tentador e simples pensarmos que o contrato por meio do Estado nos oprime e limita nosso direito à liberdade, mas após o contrato de Rousseau, o homem continua livre, pois o mesmo o permite realizar uma atividade impossibilitada em seu estado natural, conservar-se. Trata-se da regulação a liberdade.

Apesar dessas elucidações a respeito da liberdade humana pós-contrato é compreensível que estabelecido o contrato social de Rousseau, a sociedade e o conjunto de suas leis irão basear-se mais detidamente no princípio da igualdade, mesmo que ambas possam ser correlatas no pensamento de Rousseau. A primazia da igualdade é constatada no último parágrafo do Livro Primeiro do Contrato Social (1987): 
O pacto fundamental, em lugar de destruir a igualdade natural, pelo contrário substitui por uma igualdade moral e legítima aquilo que a natureza poderia trazer de desigualdade física entre os homens, que podendo ser desiguais na força ou no gênio, todos se tornam iguais por convenção e direito. (ROUSSEAU, 1987. p. 39)

Rousseau anui que a igualdade mesmo tendo cunho somente jurídico, foi instituída como direito. Por isso, a igualdade integra-se aos demais preceitos necessários para firmar a ordem social que deve permanecer incólume após o escrutínio que reconhece o contrato. A partir desse momento a igualdade é apresentada como pressuposto à liberdade e indissociável da mesma. Não obstante, nesse caso todos os cidadãos que integram o Estado passam a ser iguais, concorrendo para a efetivação dos mesmos direitos e deveres com base nas suas necessidades de estabelecer uma sociedade para que possam se conservar de maneira digna. As leis instituídas - código civil - são aplicáveis a qualquer cidadão de forma uniforme variando-se apenas as situações legais dos mesmos, pois a igualdade foi legitimada pelo contrato e como a vontade geral tende a igualdade, como afirmava Rousseau, ela torna-se direito basilar e inviolável da nova sociedade.

Em seu estado de natureza os homens desconhecem a desigualdade e os "grilhões". Contudo, sua adaptação ao meio natural os leva a atingirem um estágio de desenvolvimento no qual a igualdade natural é ameaçada, ora pela força, ora pela problemática da propriedade, conflito cujo direito ainda embrionário e não legitimado pelo contrato nesse momento impede de ser resolvido. O homem, porém, desigual em condições "materiais" continua livre, mesmo que de forma regulada. Fato corroborado pela resistência que poderia apresentar aos seus "opressores". Por isso, a necessidade de firmarse um pacto social é acrescentada a ameaça de perca de condições humanas igualitárias no estado de natureza. Por outro lado, demonstramos que o homem permanece livre antes e durante o contrato, de forma regulada e o será após ele, se o mesmo não estiver pervertido em suas bases.

Com efeito, conclui-se que o contrato é fundado com o objetivo de garantir a liberdade e igualdade humana, mas que ao ser oriundo muito mais acentuadamente da ameaça à igualdade, será esse o elemento que irá privilegiar como base inalterável. Pois a igualdade é originada do contrato, ao contrário da liberdade, que já existindo foi transfigurada pela convenção, tendo por fim alcançar a todos de maneira uniforme. Dessa forma ela é depreciada pelo direito à igualdade, ainda que meramente jurídica.

Relevante é o papel da propriedade privada em todo o processo descrito acima. No estado natural as características físicas de cada homem é o único fato que os distingue. Contudo, convencionadas a liberdade e a igualdade jurídica entre eles por meio do contrato, seus contrastes corpóreos não produzem empecilhos à igualdade social, pois o contrato não é fundado na força de cada contratante. Entretanto, o mesmo não pode afirmar-se com relação à propriedade privada. Rousseau a correlaciona com a instituição da sociedade civil e as desigualdades sociais:

O primeiro que, tendo cercado um terreno, arriscou-se a dizer: "isso é meu", e encontrou pessoas bastante simples para acreditar nele, foi o verdadeiro fundador da sociedade civil. Quantos crimes, guerras, mortes, misérias e horrores não teria poupado ao gênero humano aquele que, arrancando as estacas ou tapando os buracos, tivesse gritado a seus semelhantes: Fugi às palavras desse impostor; estareis perdidos se esquecerdes que os frutos pertencem a todos, e que a terra não é de ninguém. (ROUSSEAU, 1985. p.84) 
Apesar de criticar a propriedade privada Rousseau não refutava sua existência. É possível que o autor retorquisse aos seus inquiridores com respeito a esse tema denunciando as mazelas que um contrato em que prevaleça tal item poderia ocasionar associado a outros ainda mais vis, traçando um paralelo entre as raízes das desigualdades sociais e a propriedade privada:

Se seguirmos o progresso da desigualdade nessas revoluções, observaremos que o estabelecimento da lei e do direito de propriedade constitui seu primeiro marco; a instituição da magistratura, o segundo, e que o terceiro e último foi a transformação do poder legítimo em poder arbitrário. (ROUSSEAU, 1985. p.110)

Entre a bancarrota do estado natural e o reconhecimento por parte dos homens da necessidade de firmarem o contrato há um período em que as premissas do pacto apresentam-se aos pactuantes e são deliberadas pelos mesmos, segundo suas condições materiais objetivas. Rousseau afirma no Contrato Social (1987) que: "Renunciar à liberdade é renunciar à qualidade de homem, aos direitos da humanidade, e até aos próprios deveres." (ROUSSEAU. p. 27) Considerando que para o autor, após o contrato a liberdade é convencionada, podemos conjeturar que em algum momento intercorrente os contratantes renunciaram a sua liberdade totalmente - momento esse em que o contrato pode ser pervertido ${ }^{7}$ - para então aderir à liberdade convencionada que é estabelecida em prol da igualdade social. Esse último elemento constitui-se como inovação nas relações dos homens, na medida em que o contrato convenciona-a oficiosamente e é assegurada pela liberdade convencional, uma vez que o homem tornou-se livre para fazer o que o contrato o permite fazer e desse modo não ferir a liberdade e igualdade alheia. Portanto, é possível presumir que a liberdade passa por uma espécie de equalização com relação aos outros direitos dos homens os quais são estabelecidos pelo contrato, e ainda que o norte da equalização seja o direito a igualdade perante a lei que acaba por subscrever-se aos outros direitos. Concorrendo dessa forma para o aviltamento do homem civil, tornando verdadeira a afirmação de Maruyama:

A degradação e infelicidade do homem civil aparecem, desse ponto de vista, como perda da liberdade, porque o homem se enfraquece perdendo o direito sobre suas próprias forças, seja por tornar suas forças naturais insuficientes para a realização de suas necessidades e desejos, ou por alienar suas potencialidades e faculdades mentais. (2001. p.69)

\section{A "ética selvagem" e a transfiguração da moralidade humana}

Ao fundar a sociedade por meio do contrato, e como demonstrado, trocar a liberdade (direito natural, inalienável e que fundamenta todos os direitos legítimos dos homens) pela igualdade impelidos por sua necessidade de conservação, os homens alteram não somente tal pressuposto social, como alteram sua própria moralidade.

Sustentaremos no presente trabalho a hipótese de que ao contrário de ser acrescentada a conduta humana simultaneamente à instituição do contrato como Rousseau confiava, a moral é transfigurada pelo pacto social. E que de acordo com a natureza do contrato ela pode ser potencialmente prejudicial aos novos cidadãos, de modo que o autor afirmava igualmente que os benefícios de tal acréscimo às ações humanas seriam imensuráveis, se por vezes o contrato não contivesse natureza contrária a sua essência. 
Poderíamos ser levados a questionar: mas então que moral existia no estado natural? Uma vez que os homens bastavam a si mesmos? No estado natural, o que rege as ações dos sujeitos segundo Rousseau é a bondade. Nesse ponto,

Seu pensamento se apresenta enquanto uma grande crítica ao intelectualismo do século XVIII, e a exaltação do homem enquanto ser superior dotado de razão é substituída pela exaltação do homem natural, selvagem, ou seja, pela exaltação do homem livre.(JORGE, 2011. p.94)

Tendo o "bem" como norte à sua conduta, não podemos excluir a possibilidade de falar em uma moral "selvagem". Uma vez impelido por sua natureza à bondade, existe um ideal a ser perseguido pelo homem natural, que torna a sua moral do bem, a qual pode ser chamada de "ética selvagem".

$\mathrm{O}$ que nos permite fazer tais suposições é o ímpeto humano à organização. E igualmente a indivisibilidade do homem natural e civil, tese constatada por Maruyama nos escritos de Rousseau:

É preciso considerar, todavia, que há no Emílio um pressuposto que não aparece de modo significativo nas outras obras, o de que não é possível negar no homem real suas inclinações naturais. A idéia de uma desnaturação da natureza humana aparece também no Emílio, mas de modo muito diferente do que fora sugerido por Crocker, para quem a formação do cidadão de Rousseau implicaria, necessariamente, na extinção do homem. (MARUYAMA, 2001. p.35)

Não obstante, se as categorias de homem natural e homem civil não se excluem mutuamente - ao contrário, as inclinações naturais persistem no homem civil, porém em quantidade irrisórias - concluímos que a moral desse último é constituída e mantém resquícios das "regras de bem viver" das quais os homens naturais já se utilizavam. Portanto, há na moral do homem civilizado uma dimensão da "ética selvagem", corroborando a ideia de que já existia algum tipo de moral no estado selvagem. Nesse sentido, o estado natural transcende a simples animalidade do homem:

$\mathrm{O}$ conceito de natureza ganha dinamismo à medida que passa a se referir, não mais a um estado fixo, de dispersão e independência mútua, mas a uma natureza ou essência original que subsiste no homem que vive em sociedade e que é uma espécie de substrato às várias modificações nele ocorridas. (MARUYAMA, 2001.p.38)

Podemos afirmar então que há uma transfiguração da moralidade, pois em seu estado natural o homem baseia sua conduta e suas ações em uma moralidade do bem. Em outras palavras, o homem age de maneira benéfica a ele próprio. A partir do momento em que o contrato é estabelecido, as bases de sua moralidade tornam-se, não obstante, seus deveres e direitos como cidadão ${ }^{8}$ de um Estado constituído. Agora suas atitudes são norteadas pelas leis, pela justiça, ou seja, pelo código civil da nova sociedade e pela noção de dever inculcada agora em si por esse aparato novo e exógeno a ele, não mais apenas pelas benesses que lhe trariam.

A transfiguração da moralidade humana bem como das premissas que fundamentam sua associação, é potencialmente prejudicial aos sujeitos que estabeleceram tal acordo. Ao estabelecer tais convenções que consequentemente irão alterar e pautar sua nova moralidade e pressupostamente firmar a ordem social, os homens sujeitam-se à alienarem-se à leis, deveres e direitos vis e manipuláveis, igualmente ao caráter conferido 
então ao Estado. Essas constatações corroboram o aviltamento de toda a sociedade. Segundo Rousseau, podemos caracterizar esse desnaturamento como:

O momento em que, o direito sucedendo à violência, a natureza submetese à lei; de explicar por que encadeamento de prodígios pôde o forte decidir-se a servir ao fraco, e o povo a comprar um repouso imaginário ao preço de uma felicidade real. (ROUSSEAU, 1985. p.49)

O autor não nega que a sociedade esteja desvirtuada e distante da liberdade e igualdade desejadas. Atos de violência como esse, segundo Rousseau, não podem de forma alguma materializar-se em um código civil. Um povo só pode submeter-se a tal por tino ou livre arbítrio, pois "não imagino que moralidade possa resultar de seus efeitos." (ROUSSEAU, 1987. p.25)

Contudo, como o Contrato Social (1987) nos elucida, tais vilanias ocorrem, concedendo direitos aos homens por meio de um aparato estatal totalmente ilegítimo, que os permitem depreciar-se.

\section{Educação Política e o Contrato Social}

Assim como Rousseau adverte que o Contrato Social (1999) é um texto faccioso, "resto" de uma obra mais extensa cujo fim foram as chamas, Fortes (1976) alerta que tal obra possui dupla parcialidade, pois a mesma está contida quase que integralmente no Livro V do Emílio. Mas qual seria o objetivo de Rousseau ao anotar o Contrato Social em seu manual pedagógico?

A relevância pedagógica do Contrato Social (1999) é evidente segundo Fortes (1976) nas primeiras páginas da referida obra, nas quais Rousseau escreve:

Tendo nascido cidadão de um Estado livre e membro do soberano, embora fraca seja a influência que minha opinião possa ter nos negócios públicos, o direito de neles votar basta para impor o dever de instruir-me a seu respeito, sentindo-me feliz todas as vezes que medito sobre os governos, por sempre encontrar, em minhas cogitações, motivos para amar o governo de meu país! (ROUSSEAU, 1999, p.51-52)

Ou seja, o dever de aprender sobre política surge unido às demais obrigações dos cidadãos com relação ao Estado instituído. Transmitir o conhecimento adquirido é tarefa precípua dos sujeitos porque Rousseau concebe o soberano como ser coletivo, inalienável e indivisível.

Quando Rousseau decide que é chegada a hora de Emílio iniciar-se nos meandros políticos, notamos o escopo pragmático de seu raciocínio ora no âmbito político, ora no âmbito da educação política. Segundo Fortes (1976),

Quer se trate do homem Emílio, vivendo em uma sociedade corrompida e condenada à solidão, quer se trate de um cidadão de Genebra, vivendo em comunhão espiritual com seus compatriotas, o estudo da política se apresenta, ao que parece, como disciplina obrigatória do currículo de ambos. A reflexão teórica se subordina, desde o começo, a um objetivo pragmático: trata-se, com ela, de completar a formação do homem Emílio ou do cidadão. Esta grande ciência não é, então, tão inútil como declara Rousseau. Refletir sobre política é uma necessidade tanto para o homem como para o cidadão. (FORTES, 1976, p.71) 
Nesse sentido podemos destacar a dificuldade encontrada por Rousseau na tentativa de unir teoria à prática. De acordo com Fortes, "Rousseau abandona a teoria e enfrenta problemas concretos postos pela conjuntura histórica particular de comunidades determinadas" (FORTES, 1976, p.28) Esse autor adiciona as obras de Rousseau, insuficiência de alternativas estratégicas para a construção de uma sociedade justa e igualitária. Entretanto, é de se notar que o autor do Contrato Social (1999) nos legou quiçá o mais valioso e esquecido ensinamento acerca da construção de uma sociedade ideal, a relevância e necessidade da educação política para seus membros.

\section{A guisa de conclusão}

O âmago dos direitos positivos dos homens para Rousseau está contido no equilíbrio entre os direitos à igualdade e à liberdade. Esse equilíbrio deve ser garantido pelo dinamismo conferido ao corpo político instituído pelo contrato social, que delibera acerca das normas de conduta necessárias à vida em determinada sociedade. Entretanto, auferimos até então que o pacto social transfigura a moral humana perniciosamente, pois, ao conferir extremo valor à igualdade de direitos e deveres em detrimento da liberdade, devido às circunstâncias em que é firmada, viola a equidade basilar na qual a assembleia poderia buscar os direitos positivos dos homens.

Dessa forma a moralidade se origina como verdade consensual e posteriormente mostra-se como verdade incoerente. Em outras palavras, a moralidade surge do consenso geral à necessidade de conservar-se. Entretanto, depurando-se em contato com o real tornase incongruente às aspirações populares de igualdade, conservação e liberdade, fato que se deve as suas bases vis.

Rousseau demonstra isso no capítulo V contido no Livro Primeiro do Contrato Social (1987). Ao declarar que há evidente discrepância entre dominar pela força e ou moralmente uma multidão e administrar uma sociedade, o autor confere à moralidade papel fundamental na constituição de uma associação entre homens, ou seja, na constituição do contrato. Um só homem ao subjugar uma multidão fundará um poder ilegítimo, pois mesmo tendo sobre seu poder incontáveis sujeitos, seriam seus interesses particulares que prevaleceriam, inexistindo dessa forma como Rousseau prevê para uma associação legítima, bem público ou corpo político.

Podemos compreender de maneira mais satisfatória o papel da moralidade na constituição do contrato, avançando até a última oração do parágrafo que finda o capítulo citado: "A lei da pluralidade dos sufrágios é, ela própria, a instituição de uma convenção e supõe, ao menos por uma vez, a unanimidade.”(ROUSSEAU, 1987. p.31)

Isto é, ainda que os homens preopinem em subjugar-se ou formar uma associação legítima é necessário que haja um momento de discussão em que seja estabelecida uma convenção não só política, mas também moral. Pois, será a moral que prescreverá os hábitos e costumes indispensáveis à vida dos novos cidadãos que o contrato gerará.

Somos cônscios de que inesgotáveis são as questões que permeiam o pensamento de Rousseau. Ora por sua originalidade, ora por sua atualidade o autor é sempre citado em discussões acerca da política, educação, dos direitos e deveres do cidadão com relação à constituição do Estado entre outros temas. Contudo, realizamos a atual empresa com o intuito de suscitar dúvidas salutares à constituição e condição do cidadão para Rousseau. De forma que os cidadãos atuais possam igualmente levantar questões pertinentes a sua condição frente às instituições sociais e o Estado. Com esse teor, salientamos que num quadro de manutenção social, a troca da liberdade natural pela liberdade civil é inevitável e necessária à "manutenção da igualdade", e como simultaneamente essa última corrompe as duas primeiras, transfigurando potencialmente de maneira perniciosa ou não, os pilares 
sobre os quais deveriam estar sustentadas as cláusulas do contrato social. Ou seja, os direitos realmente naturais, legítimos e positivos dos homens. Não cabe a nós medir em que grau de intensidade tal aviltamento nos afeta. Pensamos ser de crucial relevância, esclarecermo-nos a respeito deles e como afirmava Rousseau:

Perguntar-me-ão se sou príncipe ou legislador, pra escrever sobre política. Respondo que não, e que por isso escrevo sobre política. Se fosse príncipe ou legislador, não perderia meu tempo, dizendo o que deve ser feito; haveria de fazê-lo, ou calar-me. (ROUSSEAU, 1987. p.21)

Resta-nos saber se iremos agir ou nos calar. Pois de acordo com Maruyama (2001), a consciência moral e individual é o que mantém ativa a vida política de uma determinada sociedade. Tornando estáveis, os preceitos necessários aos cidadãos para o exercício da vida pública, dentro de determinados limites.

\section{Referências}

BARROS, J. D. Igualdade - Trajetórias de uma noção no pensamento e no imaginário político. In: Revista de Filosofia. Curitiba: v. 19, n. 24 (jan./jun. 2007), p. 147-176, Champagnat, 1998.

ESPÍNDOLA, A. Rousseau e a questão do fundamento e da manutenção do poder político: diretrizes de sua posição teórica frente a Hobbes e a Locke. In: Educere Et Educare Revista de educação. Cascavel: v. I, nº I (2006), p.65-85, Edunioeste, 2008.

FORTES, Luís Roberto Salinas. Rousseau: da teoria à prática. São Paulo, Ática, 1976.

JORGE, M. C. O Homem natural como fundamento do Estado em Rousseau. In: PORTELA, Luis Cesar Yanzer, (org.). Estudos de filosofia política e do direito. Porto Alegre: Evangraf, 2011.

MARUYAMA, N. A contradição entre o homem e o cidadão: consciência e política segundo J.-J. Rousseau. São Paulo: Humanitas: Fapesp, 2001.

ROUSSEAU, J. J, 1712-1778. Discurso sobre a origem e os fundamentos da desigualdade entre os homens. Brasília, Editora Universidade de Brasília, 1985, c1981.

Do Contrato Social. 4. Ed. São Paulo: Nova Cultural, 1987.

Do Contrato Social ou Princípios do Direito Político. São Paulo - SP: Editora Nova cultural Ltda. 1999.

\section{Notas}

1 Discente do curso de Licenciatura em Pedagogia ( $3^{\circ}$ ano) pela Unioeste e membro do Grupo de estudos e pesquisas em política educacional e social - GEPPES - Unioeste.

2 Corrente de pensamento disseminada no século XVIII que enunciava entre outras idéias, a de que os homens deixam seu estado de natureza impelidos por inconveniências de tal estado e fundam a sociedade 
civil por meio de um contrato, que visa sua segurança, seu progresso e a preservação de direitos essenciais à vida em sociedade.

3 O conceito de alienação para Rousseau, se fundamenta em uma troca, uma Convenção, seja entre homens ou entre nações, que estabelece relações recíprocas de direitos e deveres entre as partes, que ocasionalmente devem abdicar de determinadas regalias em prol da convenção e seu objetivo. Portanto, não é uma troca fortuita e opressora que o autor prevê, mas uma troca que consolida determinadas relações previstas pelas partes pactuantes.

$4 \quad$ As sociedades parciais as quais Rousseau refere-se, dizem respeito às associações entre particulares que compartilham os mesmos interesses, sejam eles religiosos, comerciais, e etc. Exercendo influência sobre um número elevado de membros, em alguma forma de deliberação popular, essas sociedades parciais podem ser prejudiciais ao exercício da vontade geral, pois expressam interesses de uma parcela da população, que muitas vezes são exógenos ao Estado e portanto ao bem comum.

5 Corrente de pensamento correlata as características do liberalismo, pois, acresce o valor do indivíduo e sua liberdade, com relação às instituições sociais em geral. Em consequiência, considera o aparato estatal como meio para assegurar o direito às liberdades reguladas de cada cidadão.

6 Rousseau aufere acerca da família, que tal instituição é a mais antiga e natural sociedade que conhecemos. Todavia, apenas a necessidade de conservar-se e as condições objetivas para tanto, podem estreitar as relações dos membros dela, fato que pode ser considerado tanto no Estado natural, quanto no Estado civil. Desse modo, a palavra família utilizada no texto, extingui-se de seu caráter monogâmico, uma vez que tal característica só será observada no âmbito familiar quando as condições objetivas e os reguladores sociais o exigirem em determinada sociedade.

7 "pois o momento em que se forma um Estado, como aquele em que se forma um batalhão, é o instante em que o corpo se mostra menos capaz de resistência e mais fácil de ser destruído." (ROUSSEAU, 1999. p.124)

8 Nesse sentido, podemos afirmar que a categoria de cidadão em Rousseau é o fundamento da categoria burguesa de cidadão.

Recebido em maio/2012

Aprovado em setembro/2012 